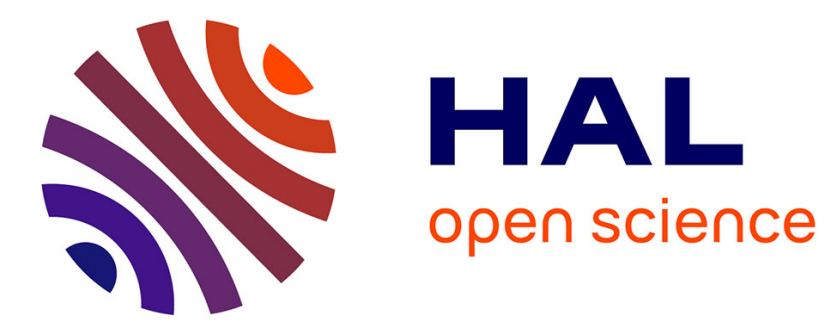

\title{
FIELD ION MICROSCOPE, IMAGING ATOM PROBE STUDY OF METALLIC GLASSES
}

\author{
H. Elswijk, P. Bronsveld, J. de Hosson
}

\section{To cite this version:}

H. Elswijk, P. Bronsveld, J. de Hosson. FIELD ION MICROSCOPE, IMAGING ATOM PROBE STUDY OF METALLIC GLASSES. Journal de Physique Colloques, 1987, 48 (C6), pp.C6-305-C6310. 10.1051/jphyscol:1987650 . jpa-00226855

\section{HAL Id: jpa-00226855 https://hal.science/jpa-00226855}

Submitted on 1 Jan 1987

HAL is a multi-disciplinary open access archive for the deposit and dissemination of scientific research documents, whether they are published or not. The documents may come from teaching and research institutions in France or abroad, or from public or private research centers.
L'archive ouverte pluridisciplinaire HAL, est destinée au dépôt et à la diffusion de documents scientifiques de niveau recherche, publiés ou non, émanant des établissements d'enseignement et de recherche français ou étrangers, des laboratoires publics ou privés. 


\author{
H.B. Elswijk, P.M. Bronsveld and J. Th. M. De Hosson \\ Department of Applied Physics, Materials Science Centre, University of Groningen, \\ Nijenborgh 18, 9747 AG Groningen, The Netherlands
}

\begin{abstract}
The application of a field ion microscope and imaging atom probe to the problem of atomic structure of metallic glasses has been investigated in two systems, $\mathrm{Ni}{ }_{40} \mathrm{Pd}_{40} \mathrm{P}_{20}$, an amorphous alloy of the type transition metalmetalloid, and Fezr, an alloy system of two transition metals, of which two compositions are studied. The spatial resolution of both techniques does not permit to probe local atomic configurations, but homogeneity on a nm scale and the presence of microcrystallites can be established.
\end{abstract}

\title{
1. INTRODUCTION
}

The atomic structure of metallic glasses has been the subject of investigation during more than two decades. Diffraction studies using $X-r a y s$, neutron and electron radiation have provided invaluable information concerning the radial distribution of atoms. Nevertheless, there is still a debate about the precise local order present in these materials. Recent measurements [1] indicate an ordering up to distances of $1 \mathrm{~nm}$, whereas models such as the dense random packing of hard spheres (DRPHS) and stereochemically defined models describe less ordered structures. Information obtained by diffraction experiments provides only a representation of the three dimensional structure, projected onto one dimension. This limits the usefullness of these measurements to test model structures. Field ion microscopy (EIM) [2] offers a possibility to view the material in atomic detail and can in principle be a very powerful tool in elucidating the atomic structure of metallic glasses. The imaging atom probe (IAP) enables us to perform a chemically sensitive measurement of the atomic distribution.

Recent publications of L. Nordentoft [3] an A.R. Bhatti et al. [4] point at severe limitations of structural investigation of metallic glasses by FIM. The low density of imaged atoms, together with the large spot size prevents imaging and resolving nearest neighbour atoms, and in $\mathrm{Fe}_{40} \mathrm{Ni}_{40} \mathrm{~B}_{20}$ and $\mathrm{Fe}_{75} \mathrm{Si}_{10} \mathrm{~B}_{15}$ glasses, surface rearrangements of boron atoms appear to take place, resulting in clusters giving rise to brightly imaging spots [4,5]. Hence, in this particular case FIM images cannot be representative of the atomic positions in the metallic glass.

In this paper we present two complementary approaches to overcome these serious problems and to explicitly investigate the limits of field ion microscopy and the imaging atom probe in this application.

Firstly, we have tackled the problem of the low density of imaged atoms by combining many subsequent FIM images taken after pulse evaporation of a few atoms of the surface each time. In this way we artificially increase the thickness of the socalled Moore shell, defined in computer simulations of FIM images as a spherical shell in which the atoms must be positioned in order to contribute to the image [6], enabling us in principle to determine positions of nearest neighbour atoms. Secondly, we investigated the image characteristics of Fezr amorphous alloys at two different compositions. In this case, the material does not contain a metalloid and the surface clustering, attributed to the boron atoms is not expected to take place. 


\section{FIM of $\mathrm{Ni}_{40} \mathrm{Pd}_{40} \mathrm{P}_{20}$}

\subsection{Material}

The material was produced by $\mathrm{HF}$ heating of a mixture of $4.62 \mathrm{gr}$. Pd powder, 3.04 gr. $\mathrm{Ni} P$ powder and $0.230 \mathrm{gr}$. Ni powder to about $1200^{\circ} \mathrm{C}$ and cooling the melt after $2 \mathrm{~min}$. $^{2}$ to room temperature under He atmosphere. The composition was homogeneous after this treatment as confirmed by standard analytical techniques (EDS/WDS). Part of the sample turned out to be amorphous even at this low cooling rate. Subsequent$1 y$ pieces of the material were remelted in a quartz tube and forced into a watercooled capillary of approximately $1 \mathrm{~mm}$ diameter by opening a valve on a He gas cylinder with a $2.5 * 10^{5} \mathrm{~Pa}$ overpressure. Electron diffraction confirmed the amorphous structure of the material obtained. The cylindrical samples were electropolished in $2 \%$ perchloric acid and $98 \%$ ethanol to produce sharp tips, suited for the FIM. Background pressure in the FIM was about $10^{-7} \mathrm{~Pa}$, while the tip was held at $60 \mathrm{~K}$. Neon and Argon were used as imaging gases at a pressure of about $10^{-3} \mathrm{~Pa}$. Imaging with Ne resulted in rapid field evaporation and often in fracture of the tip. The photograph in figure 1 shows a Ne image, figure 2 an Ar image.
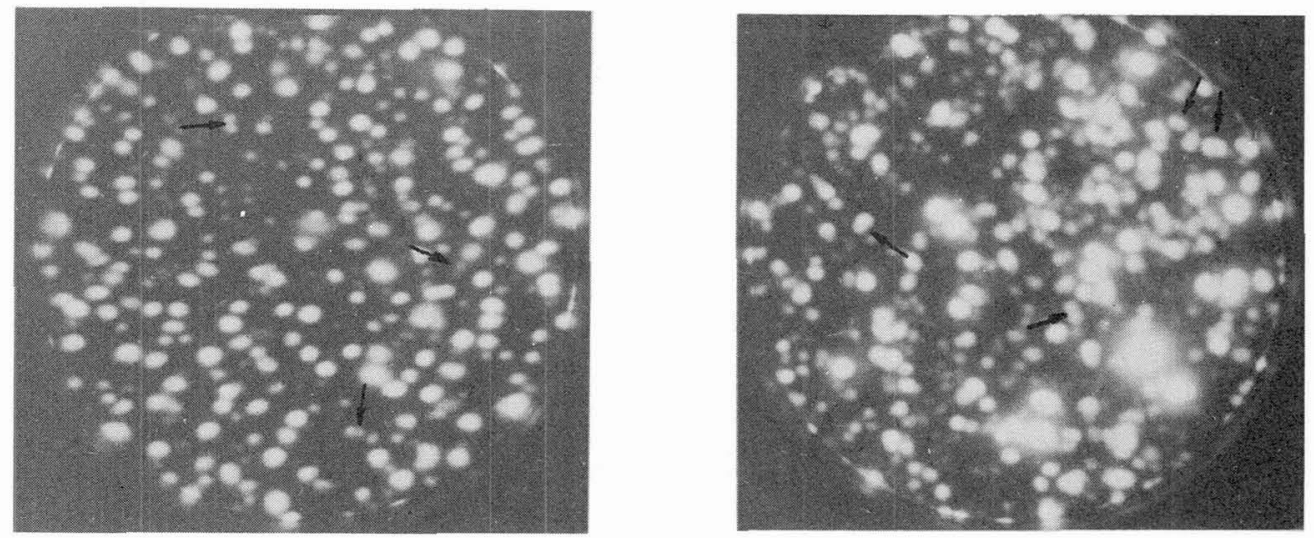

Figure 1 (Left) Ar image of amorphous $\mathrm{Ni}_{40}{ }^{\mathrm{Pd}}{ }_{40} \mathrm{P}_{20}$ at $13 \mathrm{kV}, 60 \mathrm{~K}$. Distance across is a bout $40 \mathrm{~nm}$. Arrows point at double spots.

Figure 2 (Right) Ne image of amorphous $\mathrm{Ni}_{40} \mathrm{Pd}_{40} \mathrm{P}_{2 \mathrm{P}}$ at $7.5 \mathrm{kV}, 60 \mathrm{~K}$. Distance across is about $45 \mathrm{~nm}$. Arrows point at double spots.

\subsection{Double Spots}

A peculiar phenomenon has been observed in the images i.e. the frequent occurrence of double spots. These spots appear and disappear in the image simultaneously. Approximately $23 \%$ of the spots is double in a typical Ne image and the distance between them is about $0.3-0.5 \mathrm{~nm}$. The abundance is far greater than expected from the statistical probability of neighbouring atoms located within the Moore shell at exactly the same instance. From atom probe measurements [7] Pd is known to evaporate preferentially in this alloy and only $\mathrm{Ni}$ and $\mathrm{P}$ are expected to contribute to the Ne image. We conclude that the double spots are due to the presence of the metalloid $\mathrm{P}$ in the alloy. $\mathrm{P}$ atoms may give rise to double spots as a consequence of the covalent nature of the atom. Flickering of spots caused by unstable atoms does not occur in this case, as the double spots are stable. Dimers may form at the surface. 
Table 1 Relative abundance of double spots and calculated Moore shell thickness as a function of tipvoltage with Ar image gas.

$\begin{array}{ccc}V_{\text {tip }} & \begin{array}{c}\text { abundance of } \\ \text { double spots }\end{array} & \begin{array}{c}\text { calculated } \\ \text { Moore shel1 } \\ {[\mathrm{kV}]}\end{array} \\ & & {\left[\mathrm{r}_{\mathrm{nn}}\right]} \\ 6.5 & 0.11 \pm 0.03 & 0.0026 \\ 6.9 & 0.10 \pm 0.03 & 0.0035 \\ 7.2 & 0.12 \pm 0.03 & 0.0043 \\ 7.5 & 0.11 \pm 0.02 & 0.0060 \\ 8.0 & 0.10 \pm 0.02 & 0.0084\end{array}$

The relative abundance of double spots does not depend strongly on the tip voltage and hence not on the electric field at the tip. There is however a marked difference between $\mathrm{Ne}$ and $\mathrm{Ar}$ images. The abundance changes from 0.23 to 0.11 and is thereby approximately halved. Assuming equal probabilities for all atoms to image, and knowing the preferential evaporation of Pd, we expect while imaging with Ar $20 \%$, and with Ne $33 \%$ of the imaged atoms to be $\mathrm{P}$. With Ne we thus expect a higher abundance of double spots in accordance with the observation.

\subsection{Image Density}

As the tipvoltage increases we observe an increase in the density of spots, the number of locations where the field strength suffices to ionize Ar enlarges. We have simulated FIM images of a modeled elemental metallic glass, kindly placed at our disposal by $v$. Vitek, which indicate a spot density of 1.0 atom per $\mathrm{nm}^{2}$ at a Moore shell thickness of $0.06 r_{\text {n }}$ ( $r$ denotes a nearest neighbour distance). Using this value as a calibration we calculated the Moore shell thickness from the number of atoms imaged per $\mathrm{nm}^{2}$ at some tipvoltages (see Table 1).

The Moore shell in amorphous materials appears to be extremely thin compared to values for crystalline samples being about $0.04 \mathrm{r}$ as established by Moore and Ranganathan [6]. This observation may be inherent to field ion imaging of metallic glasses because of the wide variety of local atomic configurations present. It is well known that not only the geometrical presence of an atom in the Moore shell, but also the chemical character and the local environment of the surface atoms plays an important role in the field ionization process [8]. For atoms in a crystal only a discrete number of local environments are available and thus ionization is expected to occur simultaneously at a large number of sites at the surface. Furthermore the endform of the tip is smooth as a result of the regular field evaporation. In metallic glasses there may be as many local surroundings as there are atoms present in the material and this will result in an irregular field evaporation behaviour, a corrugated endform of the tip and a broad distribution of ionization probabilities above protruding surface atoms. Therefore, the best image voltage (BIV) will vary widely over different sites. We can state that glassy metals image as though the Moore shell were thinner than in the crystalline case. From hereon we will use the term effective Moore shell to indicate the density of imaged atoms in FIM images and in combined FIM images. Obviously, a thicker effective Moore shell reveals more information.

In order to enlarge the effective Moore shell we designed a microcomputer system, capable of digitizing video signals and storing the information on magnetic tape. Subsequent images, recorded with a video camera could now be combined to give an image with a higher density of imaged atoms. 


\section{$2.4 \quad$ Results}

The centers of spots found in 180 successive images were stored as atomic positions, improving the spatial resolution in comparison with figure 2 by a factor of

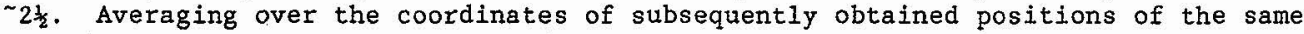
atom improves the resolution even further, eventually leading to an accuracy in the measured positions of about $0.3 \mathrm{~nm}$. The ultimate result of combining 180 images depicted in fig. 3 shows $\sim 4500$ imaged atoms at an observed area of approximately $4500 \mathrm{~nm}^{2}$. Thus we obtained an FIM image with an effective Moore shell of $\sim 0.06 \mathrm{r}_{\mathrm{nn}}$.

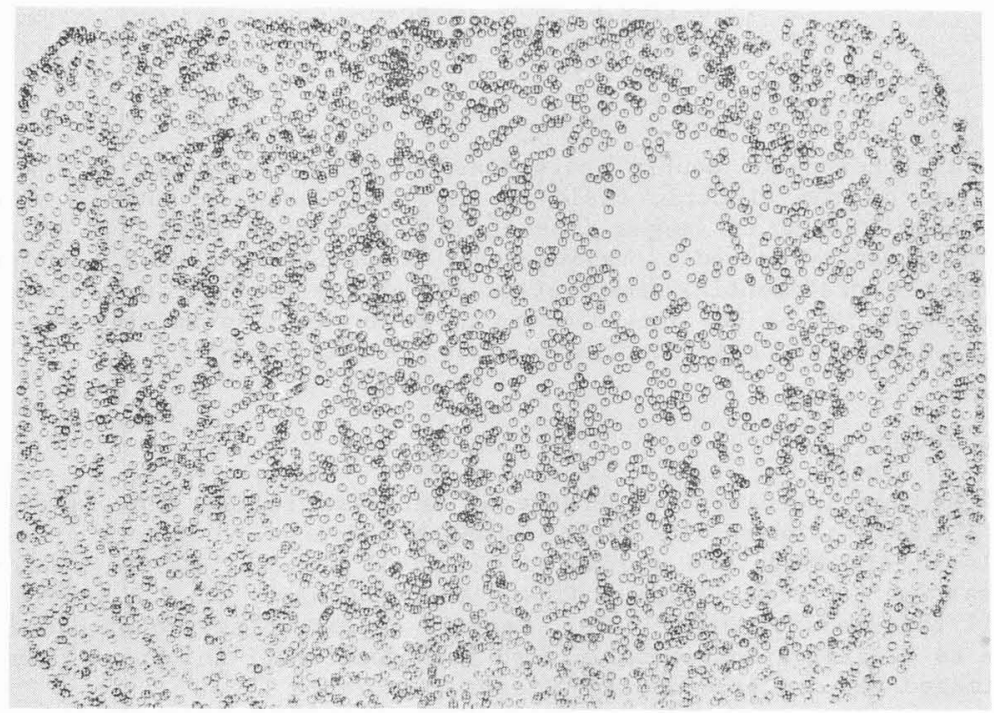

Figure 3 Atomic positions found in 180 subsequent Ar images of amorphous $\mathrm{Ni}_{40} \mathrm{Pd}_{40} \mathrm{P}_{20}$. Distance across is about $45 \mathrm{~nm}$. The empty position upper right is caused by a detector deficiency.

The atoms are displayed as circles with approximately atomic dimensions.

We can now compare directly the statistical information of the simulation with experiment. In both radial distributions the measured distance $\mathrm{R}$ is a two dimensional projection of the real distance, but as the Moore shell thickness is just a small fraction of the nearest neighbour distance this projection almost equals the real distance. In any case the two distributions can readily be compared.

Figure 4 (a) depicts the radial distribution function as measured from the simulated FIM image showing a sharp first peak and a second peak of which the splitting can not be resolved as a result of the poor statistics of one FIM image calculation. In figure 4 (b) the experimental radial distribution is depicted, the error in the horizontal axis is $30 \%$ because of the uncertainty in magnification in the FIM. This distribution shows no relevant peaks as a result of the limited resolution of the FIM. In conclusion we can state that, in order to obtain information concerning nearest neighbour correlations in $\mathrm{Ni}{ }_{40} \mathrm{Pd}_{40} \mathrm{P}_{20}$ a mere broadening of the Moore shell does not suffice, and the resolution has to be improved by using lower tip temperatures possibly enabling the use of $\mathrm{Ne}$ or He image gas and by using tips of smaller radii. 


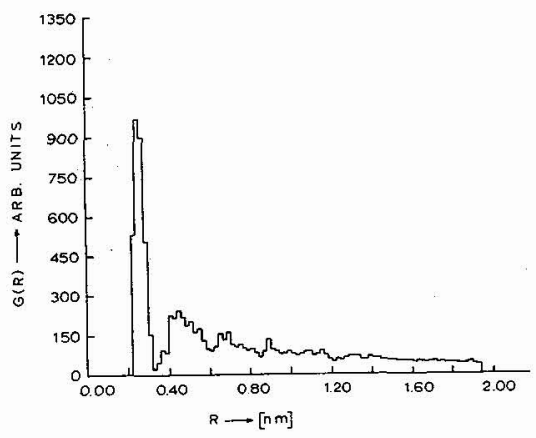

(a)

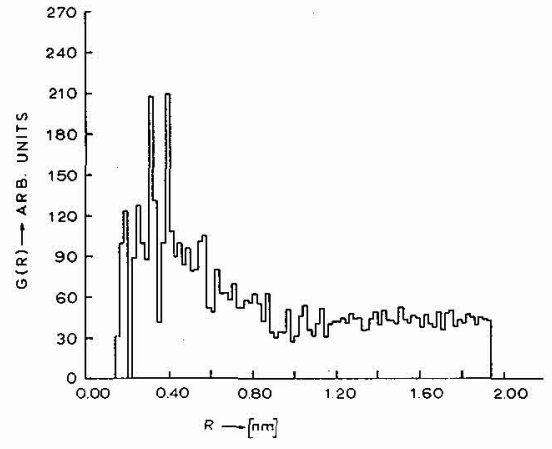

(b)

Figure 4 (a) Radial distribution measured from a simulation of an FIM image of an amorphous metal.

(b) Experimental radial distribution measured from figure 3 .

\section{FIM and IAP of FeZr Glasses}

\subsection{Materials}

The materials as supplied to us by Philips Eindhoven, were in the form of ribbons $20 \mu \mathrm{m}$ thick and $2 \mathrm{~mm}$ wide, produced by melt spinning. The ribbons were first ground from the side until an approximately square cross section was obtained. The samples were then electropolished in a mixture of $350 \mathrm{cc}$ ethanol, $60 \mathrm{cc} \mathrm{H}_{2} 0$, $50 \mathrm{cc}$ glycerin and $40 \mathrm{cc}$ perchloric acid. The tips have been imaged both with $\mathrm{Ar}$ and Ne image gas at a tip temperature of about 60K. Imaging with Ne resulted in field evaporation of both $\mathrm{Fe}_{24} \mathrm{Zr}_{76}$ and $\mathrm{Fe}_{90} \mathrm{Zr}_{10}$, the two investigated compositions. Imaging atom probe results were obtained with a set up similar as the one described by Waugh [9]. Calibration was performed with a $W$ tip.

\subsection{Results}

The amorphicity of samples could be established in the FIM by the appearance of the images. Fig. 5 for example shows an image with the tipsurface intersecting a small crystallite. Because of the higher evaporation rate of the amorphous matrix the crystallite is imaged in bright contrast.

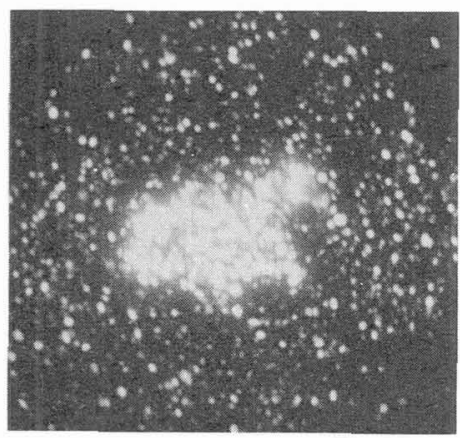

Fig. 5 Neon FIM micrograph of Zr $76^{\mathrm{Fe}_{24}}$ showing a crystallite of about $30 \mathrm{~nm}$ across in an amorphous matrix.
Fig. 6 depicts the average spot size in the FIM Ne images of $\mathrm{Fe}_{\mathrm{O}} \mathrm{Zr} \mathrm{r}_{10}$ as a function of Best Image Voltage (BIV). It can be seen that the average spot size is much larger than the resolution needed to measure correlations in the nearest neighbour range $( \pm 0.1 \mathrm{~nm})$. Tips with a radius of $5 \mathrm{~nm}$ have to be used to fulfil this requirement, tips as sharp as that are very hard to produce and will blunt rapidly in the FIM. Furthermore, these extremely sharp samples result in images containing some hundreds of atoms at most, yielding unsatisfactory statistics. To investigate in $\mathrm{Zr}_{76} \mathrm{Fe}_{24}$ the atomic distribution of $\mathrm{Zr}$ atoms we therefore used the imaging atom probe. 


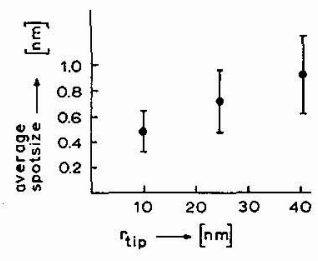

Fig. 6 Average spot size of $\mathrm{Ne}$ FIM images of $\mathrm{Fe}_{90} \mathrm{Zr}_{10}$ as a function of tipradius.

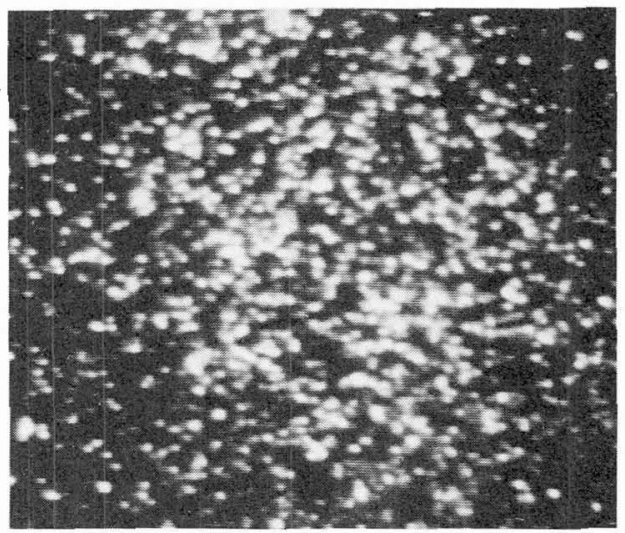

Fig. 7 Time gated image of $\mathrm{Zr}^{2+}$ ions in a $\mathrm{Zr}_{76} \mathrm{Fe}_{24}$ alloy, distance across is about $20 \mathrm{~nm}$.

Fig. 7 shows an enlarged area of the phosphorescent screen photographed from a monitor, depicting the distribution of $2 \mathrm{r}^{2+}$ ions. From this image we measured the radial distribution and it appeared that also with the imaging atom probe the spatial resolution is not sufficient for obtaining near neighbour information. Zr is found to be distributed homogeneously over the investigated area of approximately $400 \mathrm{~nm}^{2}$. The resolution as deduced from the tangential velocity of ions in equilibrium with the tip temperature is not correct, migration over the surface may precede ionization or the corrugated end form of the amorphous tip may give rise to trajectory abberrations of the ions.

\section{CONCLUSION}

Resolution problems inhibit the atomic scale correlations in metallic glasses to be investigated with a liquid nitrogen cooled field ion microscope, imaging atom probe equipment. Homogeneity can be checked on a $\mathrm{nm}$ scale and amorphicity can be established because of the ease of recognizing small crystallites. Double spots occurring frequently in images of $\mathrm{Ni}_{40} \mathrm{Pd}_{40} \mathrm{P}_{20}$ are attributed to $\mathrm{P}$ atoms concluded from the higher abundance in Ne images than in Ar images and explained by the covalent nature of the $\mathrm{P}$ atom. Low image density in FIM images of metallic glasses is attributed to the diversity in local arrangements of atoms resulting in strongly varying ionization probabilities.

\section{REFERENCES}

[ 1] P. Lamparter, S. Steeb, 'Rapidly Quenched Metals V', Vol. I (ed. S. Steeb and H. Warlimont), pp. 459-462 (1985). Amsterdam, North Holland.

[2] E. W. Muller and T. T. Tsong, 1969, Field Ion Microscopy (New York: Elsevier).

[ 3] L. Nordentoft, Phil. Mag. B 52, I 21 (1985).

[ 4 ] A. R. Bhatti, B. Cantor, D. S. Joag and G. D. W. Smith, Phil. Mag. B 52, L 63 (1985).

[ 5] J. Piller, P. Haasen, Acta Meta11. 30, 1 (1982).

[ 5] A. J.W. Moore and S. Ranganathan, Phil. Mag. 16, 723 (1967).

[7] M. Oehring and P. Haasen, Journ. de Phys., ColI. C7 - 275 (1986).

[ 8] R. C. Sanwald and J. J. Hren, Surf. Sci. 7, 197 (1967).

[9] A. R. Waugh and M. J. Southon, Surf. Sci. $\underline{68}, 79$ (1977). 